Journal Club

Editor's Note: These short, critical reviews of recent papers in the Journal, written exclusively by graduate students or postdoctoral fellows, are intended to summarize the important findings of the paper and provide additional insight and commentary. For more information on the format and purpose of the Journal Club, please see http://www.jneurosci.org/misc/ifa_features.shtml.

\title{
BDNF Signaling during Olfactory Bulb Neurogenesis
}

\author{
Ti-Fei Yuan \\ Department of Anatomy, Li Kai Shing Faculty of Medicine, The University of Hong Kong, Pokfulam, Hong Kong, China \\ Review of Bath et al. (http://www.jneurosci.org/cgi/content/full/28/10/2383)
}

One of the most prominent sites of cell renewal within the adult mammalian brain is the olfactory bulb. Newly born cells in the olfactory bulb originate in the subventricular zone and migrate through the rostral migratory stream into the core of the olfactory bulb (Alvarez-Buylla and Garcia-Verdugo, 2002). Only a small fraction of the young neurons reaching the olfactory bulb survive and differentiate into local interneurons. It has been suggested that newly generated neurons that functionally integrate into previously formed circuits may participate in fine olfactory discrimination, modification of sexual behavior, and anti-viral infection processes. However, the regulatory signaling pathways mediating adult neurogenesis are largely unknown. In a recent paper by Bath et al. (2008), the authors demonstrate a powerful link between brainderived neurotrophic factor (BDNF) signaling and survival of newly generated neurons that contribute to fine olfactory function.

The authors first set out to determine the effects of altered BDNF rates of neurogenesis by tracking proliferation and survival of newly born cells in the subventricular zone and olfactory bulb. They demonstrated that mice haploinsufficient

Received March 27, 2008; revised April 15, 2008; accepted April 15, 2008. This work was supported by the Department of Anatomy, Li Kai Shing Faculty of Medicine, The University of Hong Kong. I thank Kevin G. Bath for helpful discussions.

Correspondence should be addressed to Ti-Fei Yuan, Department of Anatomy, Li Kai Shing Faculty of Medicine, The University of Hong Kong, 21 Sassoon Road, Pokfulam, Hong Kong, China. E-mail: yuantf@hku.hk.

DOI:10.1523/JNEUROSCI.1327-08.2008

Copyright $\odot$ 2008 Society for Neuroscience $\quad$ 0270-6474/08/285139-02\$15.00/0 for BDNF had decreased survival of newly born neurons but no alteration in rates of proliferation [Bath et al. (2008), their Fig. 1 (http://www.jneurosci.org/cgi/content/ full/28/10/2383/F1)]. To test whether this effect was resulting from mere BDNF levels or regulated release of BDNF, they used a newly developed transgenic mouse $\left(\mathrm{BDNF}^{\mathrm{Met} / \mathrm{Met}}\right)$ that they have previously shown to have a deficiency in activitydependent BDNF secretion (Chen et al., 2006). In these mice, the authors also found a selective impairment in survival of newly born granule cells in the olfactory bulb, suggesting a role for regulated release of BDNF in controlling the survival of newly born neurons.

To test which downstream receptor of BDNF was responsible for controlling neurogenesis, the authors used mice in which either of BDNF's receptors (TrkB or p75) were genetically knocked out. The authors showed that the observed BDNF effects were specific to the TrkB signaling pathway. Furthermore, using immunohistochemistry, the authors showed that activated TrkB was highly expressed in neurogenic areas [Bath et al. (2008), their Fig. 3 (http://www.jneurosci.org/cgi/ content/full/28/10/2383/F3)] and localized to type A migrating neuroblasts [Bath et al. (2008), their Fig. 4C,D (http:// www.jneurosci.org/cgi/content/full/28/ 10/2383/F4)].

In previous studies, it has been suggested that olfactory discrimination learning increases the survival of newly generated neurons inside the olfactory bulb (Alonso et al., 2006; Mandairon et al., 2006) and that ablation of olfactory bulb impairs the survival, rather than the proliferation, of subventricular-zonederived neural precursors (Kirschenbaum et al., 1999). Bath et al. (2008) therefore examined the role of activity-dependent release of BDNF in olfactory bulb neurogenesis. In secretion-deficient BD$\mathrm{NF}^{\mathrm{Met} / \mathrm{Met}}$ mice, the authors observed decreased TrkB receptor activation in the subventricular zone [Bath et al. (2008), their Fig. 6G (http://www.jneurosci.org/ cgi/content/full/28/10/2383/F6)]. These data led the authors to conclude that activity-dependent BDNF secretion is required for TrkB activation in the subventricular zone.

In addition to the $\mathrm{TrkB}$ receptor, BDNF also signals through the 775 receptor. The authors showed that p75 knockout mice did not differ from wild-type control mice in rate of cell proliferation in the subventricular zone or survival in the olfactory bulb [Bath et al. (2008), their Fig. 1 (http://www.jneurosci.org/cgi/ content/full/28/10/2383/F1)] and that p75 receptors are localized to proliferative type C precursor cells [Bath et al. (2008), their Fig. $5 A-C$ (http://www.jneurosci. org/cgi/content/full/28/10/2383/F5)]. Other researchers have proposed that $\mathrm{p} 75$ receptor expression defines a population of BDNF-responsive proliferating cells in the subventricular zone (Young et al., 2007) and may mediate BDNF-induced differentiation of neural precursor cells (Hosomi et al., 2003). It would be useful to know whether these effects are also ol- 
factory activity dependent or can be mediated by odor enrichment.

Bath et al. (2008) next examined the effects of BDNF signaling on neuroblast migration. They identified a gradient of BDNF within the olfactory bulb [Bath et al. (2008), their Fig. 2 (http://www. jneurosci.org/cgi/content/full/28/10/ 2383/F2)]. Furthermore, they demonstrated a significant decrease in BDNF levels in $\mathrm{BDNF}^{\mathrm{Met} / \mathrm{Met}}$ mice, which they believe may have impacted this gradient and thus consistently disrupted neuroblast migration (Fig. 1).

It has previously been demonstrated that newly generated neurons in olfactory bulb may participate in fine odor discrimination (Gheusi et al., 2000). In the current paper, the authors showed that BDNF-haploinsufficient, TrkB-haploinsufficient, and $\mathrm{BDNF}^{\text {Met/Met }}$ lines of mice did not spontaneously discriminate between odorants [Bath et al. (2008), their Fig. 7 (http://www.jneurosci.org/cgi/ content/full/28/10/2383/F7)]. These data suggest to us that activity-dependent BDNF-TrkB signaling is critical for fine olfactory function, possibly mediated by olfactory bulb neurogenesis. However, these data remain correlative, and the detailed mechanisms underlying these olfactory deficits are still unknown. It is possible that the decreased levels of BDNF inside the olfactory bulb in these lines of mice [Bath et al. (2008), their Fig. 2 (http://www.jneurosci.org/cgi/content/ full/28/10/2383/F2)] may also significantly impact olfactory function independent of the observed alterations in neurogenesis. The authors argue against this, because they observe no alterations in odor detection, initial investigation time for the habituating odorant, or the ability of these animals to habituate to an odorant.

With this report, Bath et al. (2008) have provided detailed insights into the role of BDNF signaling in olfactory bulb neurogenesis and provided the first link between disruptions in neurotrophin signaling and olfactory behavioral performance. These findings, combined with previous reports from their group (Bath and Lee, 2006; Chen et al., 2006), implicating a role for the BDNF polymorphism

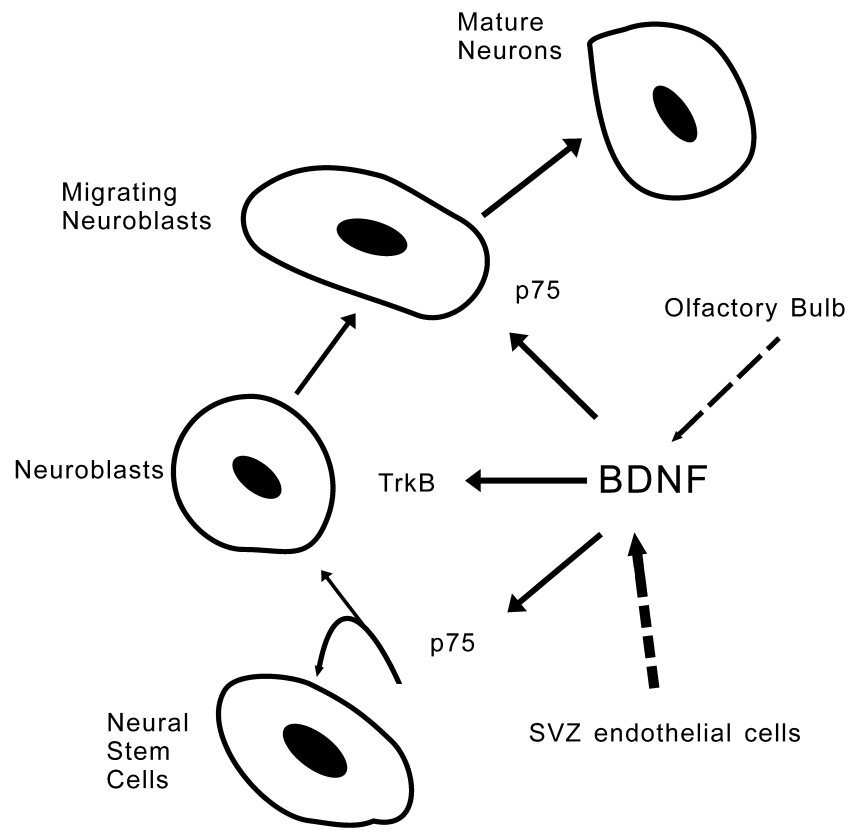

Figure 1. BDNF signaling regulates multiple steps in the control of olfactory bulb neurogenesis: proliferation, migration, differentiation, and survival. TrkB receptor and p75 receptor lead to distinct downstream signaling pathways that participate in different regulation. The major sources of BDNF are subventricular zone (SVZ) endothelial cells, whereas olfactory bulb-derived BDNF secretion has been proved to be activity dependent in the study by Bath et al. (2008).

(Val66Met) in altered brain structure and function, have provided evidence that regulated release of $\mathrm{BDNF}$ in the CNS is critical for detecting and processing changes in the environment. This work may contribute significantly to the understanding of symptomatology of a variety of neuropsychiatric disorders and may provide insights for developing novel treatments for such disorders, both genetically and pharmacologically.

\section{References}

Alonso M, Viollet C, Gabellec MM, Meas-Yedid V, Olivo-Marin JC, Lledo PM (2006) Olfactory discrimination learning increases the survival of adult-born neurons in the olfactory bulb. J Neurosci 26:10508-10513.

Alvarez-Buylla A, Garcia-Verdugo JM (2002) Neurogenesis in adult subventricular zone. J Neurosci 22:629-634.

Bath KG, Lee FS (2006) Variant BDNF (Val66Met) impact on brain structure and function. Cogn Affect Behav Neurosci 6:79-85.

Bath KG, Mandairon N, Jing D, Rajagopal R, Kapoor R, Chen ZY, Khan T, Proenca CC, Kraemer R, Cleland TA, Hempstead BL, Chao MV, Lee FS (2008) Variant brain-derived neurotrophic factor (Val66Met) alters adult olfactory bulb neurogenesis and spontaneous olfactory discrimination. J Neurosci 28:2383-2393.

Chen ZY, Jing D, Bath KG, Ieraci A, Khan T, Siao CJ, Herrera DG, Toth M, Yang C, McEwen BS, Hempstead BL, Lee FS (2006) Genetic variant BDNF (Val66Met) polymorphism alters anxiety-related behavior. Science 314: $140-143$.

Gheusi G, Cremer H, McLean H, Chazal G, Vincent JD, Lledo PM (2000) Importance of newly generated neurons in the adult olfactory bulb for odor discrimination. Proc Natl Acad Sci USA 97:1823-1828.

Hosomi S, Yamashita T, Aoki M, Tohyama M (2003) The p75 receptor is required for BDNF-induced differentiation of neural precursor cells. Biochem Biophys Res Commun 301:1011-1015.

Kirschenbaum B, Doetsch F, Lois C, AlvarezBuylla A (1999) Adult subventricular zone neuronal precursors continue to proliferate and migrate in the absence of the olfactory bulb. J Neurosci 19:2171-2180.

Mandairon N, Sacquet J, Garcia S, Ravel N, Jourdan F, Didier A (2006) Neurogenic correlates of an olfactory discrimination task in the adult olfactory bulb. Eur J Neurosci 24:3578-3588.

Young KM, Merson TD, Sotthibundhu A, Coulson EJ, Bartlett PF (2007) p75 neurotrophin receptor expression defines a population of BDNF-responsive neurogenic precursor cells. J Neurosci 27:5146-5155. 